\title{
HYPERSPECTRAL ANALYSIS OF RICE PHENOLOGICAL STAGES IN NORTHEAST CHINA
}

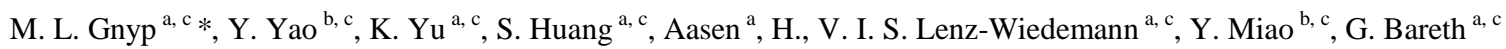 \\ ${ }^{a}$ Institute of Geography (GIS \& RS Group), University of Cologne, 50923 Cologne, Germany - \\ (mgnyp1, kyu, helge.aasen, victoria.lenz, g.bareth)@uni-koeln.de, shuang331919@gmail.com \\ ${ }^{\mathrm{b}}$ College of Resources and Environmental Sciences, China Agricultural University, Beijing, 100094, China - \\ yyk719@163.com,ymiao2007@gmail.com \\ ${ }^{\mathrm{c}}$ ICASD - International Center for Agro-Informatics and Sustainable Development, www.icasd.org
}

KEY WORDS: Agriculture, Crop, Hyperspectral, Estimation, Infrared, Multitemporal

\begin{abstract}
:
The objective of this contribution is to monitor rice (Oryza sativa L., irrigated lowland rice) growth with multitemporal hyperspectral data during different phenological stages in Northeast China (Sanjiang Plain). Multitemporal hyperspectral data were measured with field spectroradiometers (ASD Inc.: QualitySpec and FieldSpec3) for two field experiments and nine farmers' fields. The field measurements were carried out together with corresponding measurements of agronomic data (aboveground biomass [AGB], Leaf Area Index [LAI], number of tillers). Eight selected standard hyperspectral vegetation indices (VIs), proved in several studies to be highly correlated with AGB or LAI, were calculated on the measured experimental field data. Additionally, the best two-band combinations for the Normalized Ratio Index (NRI) were determined. The results indicate that the NRI performed better than the selected standard VIs at the stages of stem elongation, booting and heading and also across all stages. Especially during the stem elongation stage $\left(R^{2}=0.76\right)$ and across all stages $\left(R^{2}=0.70\right)$, the NRI performed best. When applying the NRI on the farmers' field data, the performance was lower $\left(\mathrm{R}^{2}<0.60\right)$. Overall, the sensitive individual wavelengths $( \pm 10 \mathrm{~nm})$ for the best two-band combinations were detected at 711 and $799 \mathrm{~nm}$ (for tillering stage), 1575 and $1678 \mathrm{~nm}$ (for stem elongation stage), 515 and $695 \mathrm{~nm}$ (for booting stage), and 533 and $713 \mathrm{~nm}$ (for all stages). The results suggest that hyperspectral-based methods can estimate paddy rice AGB with a satisfying accuracy. In the context of precision agriculture, the findings are useful for future development of new hyperspectral devices such as scanners or cameras which could be fixed on tractors or unmanned aerial vehicles (UAVs).
\end{abstract}

\section{INTRODUCTION}

Rice is a staple grain and accounts for over $40 \%$ of the grain protein production in China. It is the main food not only in China but also in other highly populated countries in Asia. For securing food production and quality, the estimation of agronomic parameters is an important task for decision support in rice cultivation. Agronomic parameters such as crop aboveground biomass (AGB) or Leaf Area Index (LAI) are considered as the major factors for the determination of the final yield because of their influence on the grain production at each growth stage (Shibayama \& Munakata, 1986). Estimation of growth parameters at different phenological stages is a common method in remote sensing.

Especially high resolution hyperspectral sensors offer valuable information in the UV, Visible and NIR/SWIR region of the electromagnetic spectrum. Their continuous acquisition of all reflectance values in a spectral range has a major advantage over multispectral sensors collecting broad band (Milton et al., 2009). Portable handheld spectroradiometers are fast and nondestructive hyperspectral devices. They are applied more and more to estimate plant AGB (Shibayama \& Munataka, 1986; Serrano et al., 2000; Osborne et al., 2002; Hansen \& Schjoerring, 2003; Chen et al., 2009; Psomas et al., 2011).

Deriving information from crop reflectances, the in-season and within-field temporal and spatial crop development and growth can be described. Combined with agronomic parameters (e.g. biomass), crop management information systems (Laudien et al., 2006) or empirically based crop models can be developed (Todd et al., 1998), which are usually based on vegetation indices (VIs). For process-based and spatially distributed agroecosystem modelling (e.g. Lenz-Wiedemann et al., 2010), crop parameters derived from remote sensing data can be applied to validate model results on the regional scale.

Numerous VIs considering various equations and spectral bands or specific wavelengths are published. The most classical VI is the Normalized Difference Vegetation Index (NDVI). New VIs may be detected by selecting the best two-band combinations. This method was introduced by Thenkabail et al. (2000) to determine the best suited spectral bands for predicting the biophysical quantities of crops. Their method was applied with promising results in studies by e.g. Hansen \& Schjoerring (2003), Zhu et al. (2008), Stroppiana et al. (2009), Koppe et al. (2010), Li et al. (2010), Psomas et al. (2011), Song et al. (2011), and Tian et al. (2011).

The aim of this study is to compare selected standard VIs with the best two-band combinations of Normalized Ratio Indices (NRIs) for estimating paddy rice AGB in Northeast China at different phenological stages and across all stages. First, based on experimental field measurements of spectra and biomass, the best two-band combinations for the NRI are derived. The results are then compared with the performance of the standard VIs. Finally, the NRIs are applied on farmers' fields for validation.

\footnotetext{
* Corresponding author.
} 


\section{MATERIALS AND METHODS}

\subsection{Study area and test sites}

The research was carried out at the Qixing farm $\left(47.2^{\circ} \mathrm{N}\right.$ $\left.132.8^{\circ} \mathrm{E}\right)$, Heilongiiang Province, China. The farm has an area of approx. 150000 ha and is located at the lower stretch of the Songhua River, approx. $80 \mathrm{~km}$ south of the Amur River (Fig. 1). The farm is part of the Sanjiang Plain, which belongs to the temperate zone and is characterized by a sub-humid continental monsoon climate. The main crop of the farm is rice ( $80 \%$ of the agricultural area). Besides rice, maize, soybean and summer wheat are cultivated. The rice fields belong to the northernmost cropping rice system in China and worldwide.

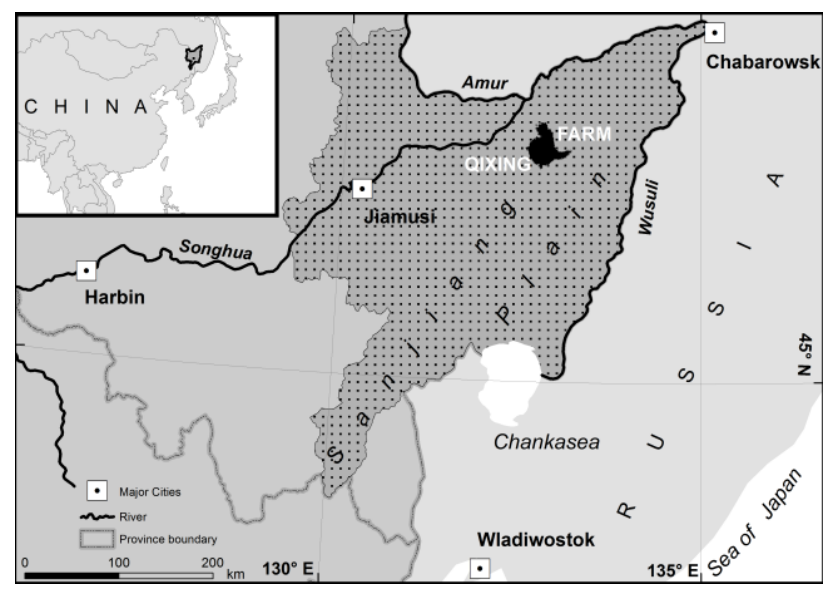

Figure 1. Location of the Qixing farm in the Sanjiang Plain

The rice is sown in greenhouses in mid of April, is transplanted after the frost period to the field from mid to end of May and is harvested around end of September. The fields are flooded and manured with $\mathrm{N}$ fertilizer before transplanting the seedlings. 4 to 5 seedlings (120-150 seedlings $\left./ \mathrm{m}^{2}\right)$ are planted at one position forming a so-called hill. Additional $\mathrm{N}$ fertilizer is applied during the stages tillering, stem elongation and heading.

Two experimental fields were selected in 2007, 2008 and 2009. Each year, the experiments were carried out at the two same sites (Keyansuo and Qixing research station). Each experiment had a split-plot design with three or four repetitions where each repetition had 5 or $7 \mathrm{~N}$ fertilizer treatments (total $\mathrm{N}$ input): 0 , $60,75,90,105,120$, and $150 \mathrm{~kg} \mathrm{~N} \mathrm{ha}^{-1}$ in 2007 and $0,35,70$, 105, and $140 \mathrm{~kg} \mathrm{~N} \mathrm{ha}^{-1}$ in 2008 and 2009. The plot size was approx. $20 \mathrm{~m}^{2}$. All field experiments used the rice cultivar Kongyu 131 with averaged 28 hills $/ \mathrm{m}^{2}$. In addition to these field experiments, 9 farmers' fields were selected as test sites. They were managed by the farmers according to their usual practices. The size of these fields varied from 12 ha to 27 ha. In most cases, the cultivar Kongyu131 was planted (28 hills $\left./ \mathrm{m}^{2}\right)$. Each year, the selected farmers' fields were located at varied sites.

\subsection{Data collection}

At the beginning of each field campaign, the average tiller number of a hill was determined per plot in order to measure the reflectance of representative plants. Canopy spectral reflectance was measured with the spectroradiometer ASD QualitySpec ${ }^{\circledR}$ Pro in the wavelength domain of 350-1800 nm in 2007 and 2009, and an ASD FieldSpec3 ${ }^{\circledR}$ Pro (both by Analytical Spectral Devices, Inc., Boulder, CO, USA) in the domain of 350-2500 nm in 2008 and 2009. The reflectance measurements were taken from 9 a.m. to 1 p.m. LMT, preferably under cloudless conditions. Every 10-15 minutes, calibration measurements were done with a white reference panel $\left(\mathrm{BaSO}_{4}\right)$ and were repeated depending on illumination changes. With a default field of view of $25^{\circ} 5-8$ hills were captured by the device. A measuring height of $1 \mathrm{~m}$ above the canopy was applied during all field campaigns. Six spectral measurements were taken in each plot and averaged in order to reduce the atmospheric influence and field conditions .

AGB (6 hills per plot at an early stage and 3 hills per plot at booting and heading stage) was collected directly after hyperspectral data acquisition at the stages tillering, stem elongation, booting, and heading. All plant samples were oven dried at $105{ }^{\circ} \mathrm{C}$ for 30 minutes and then dried at $70{ }^{\circ} \mathrm{C}$ until constant weight. LAI was estimated from destructive sampled leaves by cutting $3 \mathrm{~cm}$ length from 20 randomly selected leaves for each plot at stem elongation, booting and heading stage in 2009 to examine the relationship between LAI and AGB.

\subsection{Selection of vegetation indices and data analysis}

Three groups of standard VIs were analyzed (Tab. 1): NDVI, Difference Vegetation Indices (DVI) and Ratio Vegetation Indices (RVI). Only bands, reported to be correlated with AGB or LAI, were chosen in this study. These selected narrow bands are centred at 550, 565, 708, 800, 950, 1100 and $1200 \mathrm{~nm}$ (Shibayama \& Munataka, 1986; Shibayama \& Munataka, 1989; Hansen \& Schjoerring, 2003; Nguyen et al., 2006; Wang et al., 2008). Additionally two other VIs were selected: Modified Triangular Vegetation Index (MTVI) and Optimized SoilAdjusted Vegetation Index (OSAVI). The modified TVI by Haboudane et al. (2004) is suitable for LAI estimation. In addition to standard VIs, the best two-band combinations method suggested by Thenkabail et al. (2000), was used to determinate the best two-band combinations for the NRI.

\begin{tabular}{lll}
\hline VI & Formulation & Reference \\
\hline NDVI & $\left(\mathrm{R}_{708}-\mathrm{R}_{565}\right) /\left(\mathrm{R}_{708}+\mathrm{R}_{565}\right)$ & Hansen \& Schjoerring (2003) \\
DVI & $\mathrm{R}_{1100}-\mathrm{R}_{1200}$ & Shibayama \& Munataka (1989) \\
DVI & $\mathrm{R}_{950}-\mathrm{R}_{650}$ & Shibayama \& Munataka (1986) \\
DVI & $\mathrm{R}_{800}-\mathrm{R}_{550}$ & Buschmann \& Nagel (1993) \\
RVI & $\mathrm{R}_{1100} / \mathrm{R}_{660}$ & Zhu et al. (2008) \\
RVI & $\mathrm{R}_{950} / \mathrm{R}_{650}$ & Shibayama \& Munataka (1986) \\
MTVI & $1.2 *\left[1.2 *\left(\mathrm{R}_{800}-\mathrm{R}_{550}\right)-2.5\left(\mathrm{R}_{670}-\mathrm{R}_{550}\right)\right]$ & Haboudane et al. (2004) \\
OSAVI & $(1+0.16) *\left(\mathrm{R}_{800}-\mathrm{R}_{670}\right) /\left(\mathrm{R}_{800}+\mathrm{R}_{670}+0.16\right)$ & Rondeaux et al. (1996) \\
\hline
\end{tabular}

Table 1. Standard VIs evaluated in this study 
The VIs calculated by this method are also known in the literature as Normalized Ratio Index (NRI), optimized NDVI, or Normalized Difference Indices (NDI). All possible combinations were computed from the wavelengths in the domain of 350-1800 nm (see Eq. 1). The bands from 1330 to $1480 \mathrm{~nm}$, and 1750 to $1800 \mathrm{~nm}$ were excluded from the further analysis, due to the noises caused by the water absorption in the NIR/SWIR domain. The NRI is defined as:

$$
\mathrm{NRI}_{(\lambda 1, \lambda 2)}=\left(\mathrm{R}_{\lambda 1}-\mathrm{R}_{\lambda 2}\right) /\left(\mathrm{R}_{\lambda 1}+\mathrm{R}_{\lambda 2}\right)
$$

where (reflectance in wavelength) $R_{\lambda 1}>R_{\lambda 2}$

The combinations were calculated with a Java programme, analyzed and plotted as a contour diagram by MATLAB 7.0 software (The MathWorks, Inc., Natick, MA, USA).

\section{RESULTS}

\subsection{Descriptive statistics of measured AGB}

The AGB for the experimental fields ranges from 0.1 to $14.1 \mathrm{t} \mathrm{ha}^{-1}$ across all growth stages (Tab. 2). The canopy has a high variation in AGB (CV of 22-57\%), especially during the stages $\mathrm{T}$ and $\mathrm{B}$, and a lower $\mathrm{AGB}$ variation ( $\mathrm{CV}$ of $16-36 \%$ ) during the stages $\mathrm{B}$ and $\mathrm{H}$. Significant is the temporal variation between the three years with a low AGB production in 2009 with a mean AGB value of $0.8-7.0 \mathrm{tha}^{-1}$, and a high in 2007 with a mean AGB value of 1.3-7.6 tha $\mathrm{h}^{-1}$ The highest AGB is observed for the heading stage with $14.1 \mathrm{t} \mathrm{ha}^{-1}$ in 2008. The varied treatments are not studied separately. The high number of measurements covering a wide range of AGB values provides an ideal basis for the spectral analysis.

\begin{tabular}{|c|c|c|c|c|c|c|c|}
\hline & Stage & $\mathrm{n}$ & $\begin{array}{l}\text { Min } \\
\left(\mathrm{t} \mathrm{ha}^{-1}\right)\end{array}$ & Max & Mean & SD & $\begin{array}{l}\mathrm{CV} \\
(\%) \\
\end{array}$ \\
\hline \multirow{4}{*}{ 용 } & $\mathrm{T}$ & 58 & 0.7 & 1.9 & 1.3 & 0.3 & 22.1 \\
\hline & $\mathrm{S}$ & 53 & 0.7 & 5.1 & 2.4 & 1.4 & 57.2 \\
\hline & B & 51 & 3.0 & 7.9 & 5.7 & 1.1 & 19.7 \\
\hline & $\mathrm{H}$ & 114 & 3.3 & 12.4 & 7.6 & 2.0 & 26.1 \\
\hline \multirow{4}{*}{$\stackrel{\infty}{8}$} & $\mathrm{~T}$ & 40 & 0.1 & 1.8 & 0.9 & 0.5 & 50.5 \\
\hline & $\mathrm{S}$ & 40 & 0.9 & 2.9 & 1.6 & 0.5 & 31.3 \\
\hline & B & 88 & 2.9 & 8.8 & 5.3 & 1.4 & 25.6 \\
\hline & $\mathrm{H}$ & 88 & 4.4 & 14.1 & 9.0 & 1.8 & 20.4 \\
\hline \multirow{4}{*}{ ஓి } & $\mathrm{T}$ & 91 & 0.2 & 1.6 & 0.8 & 0.3 & 41.3 \\
\hline & $\mathrm{S}$ & 95 & 0.3 & 2.2 & 1.2 & 0.5 & 42.0 \\
\hline & B & 95 & 1.4 & 6.6 & 3.5 & 1.3 & 36.1 \\
\hline & $\mathrm{H}$ & 94 & 4.6 & 9.7 & 7.0 & 1.1 & 16.4 \\
\hline \multirow{4}{*}{$\bar{z}$} & $\mathrm{~T}$ & 189 & 0.1 & 1.9 & 1.0 & 0.4 & 40.8 \\
\hline & $\mathrm{S}$ & 188 & 0.3 & 5.1 & 1.6 & 1.0 & 59.3 \\
\hline & B & 234 & 1.4 & 8.8 & 4.7 & 1.6 & 34.3 \\
\hline & $\mathrm{H}$ & 296 & 3.3 & 14.1 & 7.8 & 1.9 & 24.0 \\
\hline
\end{tabular}

$\mathrm{T}=$ Tillering, $\mathrm{S}=$ Stem elongation, $\mathrm{B}=$ Booting, $\mathrm{H}=$ Heading

Table 2. Descriptive statistics of AGB (dry matter) on the experimental fields for different growth stages and years; with

$\mathrm{SD}=$ standard deviation and $\mathrm{CV}=$ coefficient of variation

\subsection{Relationship between AGB and LAI}

Because VIs related to LAI were calculated and tested for AGB estimation, the relationship between measured LAI and AGB was investigated. Two selected figures are shown in Fig. 2a) for the stem elongation stage $\left(R^{2}=0.96\right)$ and in Fig. $\left.2 b\right)$ across all available stages $\left(R^{2}=0.80\right)$ in 2009 . Except for two, the values are all in the $99 \%$ confidence interval. The appendant values for the booting and heading stage are $\mathrm{R}^{2}=0.90$ and $\mathrm{R}^{2}=0.67$. As it is to be expected, the linear relationship between these two agronomic parameters shows very high and then decreasing $\mathrm{R}^{2}$ values from the early to the late stages. Due to that relation, VIs which are suitible for LAI estimation can be applied for AGB estimation. In the following, the relationship between AGB and the reflectance at single wavelengths were discussed.
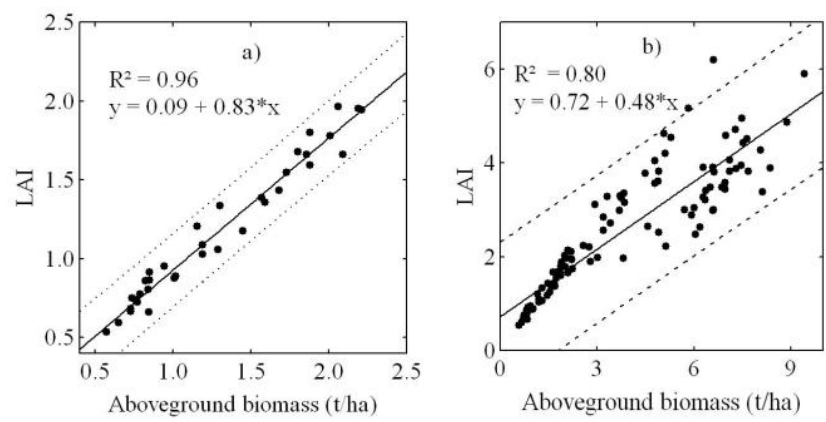

Figure 2. Relationship between AGB and LAI for the stem elongation stage 2009 (a) and all available stages 2009 (b) with $\mathrm{p}=0.99$ for the confidence bands

\subsection{Relationship between AGB and reflectances at single wavelengths}

The coefficients of determination $\left(\mathrm{R}^{2}\right)$ between $\mathrm{AGB}$ and the 1450 individual narrow bands were plotted for the single several years and across all years in Fig. 3. The noise of water absorption bands was excluded. In general, the relationship seems to be similar in all three years and indicates the same sensitive wavelengths. The largest $\mathrm{R}^{2}$ values $(>0.4)$ were detected centred at $670,920,1100$ and $1275 \mathrm{~nm}( \pm 10 \mathrm{~nm})$, and the lowest $\mathrm{R}^{2}$ values (almost 0 ) are centred at 570, 700, 1125, and $1500 \mathrm{~nm}( \pm 10 \mathrm{~nm})$. The 2007 graph for the relationship between AGB and the individual wavelength shows some noises in the UV, NIR and SWIR domains which are also in the graph across all years, but not so pronounced in the 2008 and 2009 data. For all the following spectral analyses, the three years are considered together.

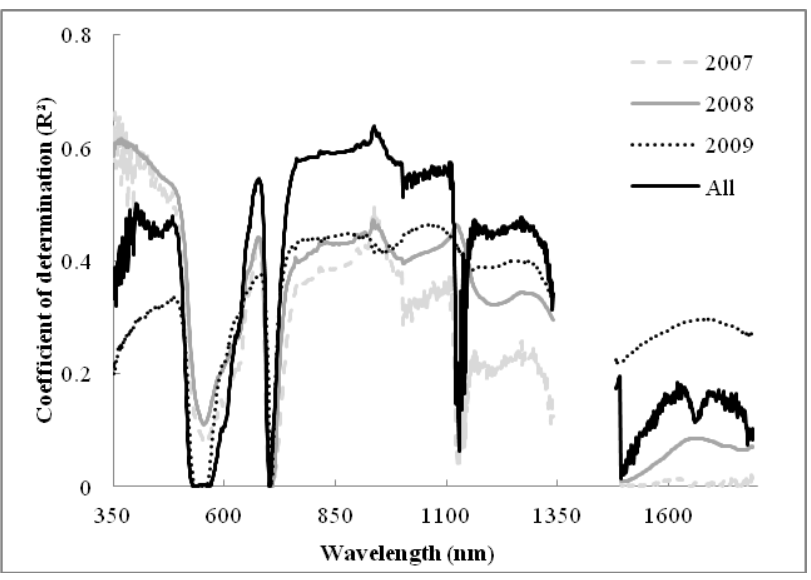

Figure 3. Coefficient of determination $\left(\mathrm{R}^{2}\right)$ for the relationship between AGB and the reflectance at a single wavelength 


\subsection{Performance of published hyperspectral VIs}

The performance of the eight selected standard VIs is given for each stage and across all stages in Tab. 3 for all three years' data. Generally, the $\mathrm{R}^{2}$ values show moderate but significant results $(0.30-0.51)$ at the first three stages, except for the $\operatorname{NDVI}_{(708,565)}$. The best estimators for AGB are OSAVI at tillering stage $\left(\mathrm{R}^{2}=0.45\right)$, MTVI at stem elongation stage $\left(\mathrm{R}^{2}=0.51\right)$ and $\mathrm{DVI}_{(800,550)}$ and OSAVI at booting stage $\left(\mathrm{R}^{2}=0.48\right)$. Almost no relationship exists at heading stage $\left(\mathrm{R}^{2}<0.1\right)$ for the seven of the eight VIs. Across all years and all stages the $\operatorname{NDVI}_{(708,565)}$ shows the best performance $\left(\mathrm{R}^{2}=0.68\right)$. But also the other VIs come with high $\mathrm{R}^{2}$ values $(0.54-0.62)$. VIs with the best performance at early stages such as OSAVI and MTVI have a lower performance across all stages.

\begin{tabular}{llllll}
\hline & & \multicolumn{4}{c}{ Stage } \\
& $\mathrm{T}$ & $\mathrm{S}$ & $\mathrm{B}$ & $\mathrm{H}$ & All \\
$\mathrm{VI}$ & $\mathrm{n}=189$ & $\mathrm{n}=188$ & $\mathrm{n}=234$ & $\mathrm{n}=297$ & $\mathrm{n}=908$ \\
\hline $\operatorname{NDVI}_{(708,565)}$ & 0.04 & 0.01 & 0.15 & 0.19 & 0.68 \\
$\operatorname{DVI}_{(1100,1200)}$ & 0.35 & 0.39 & 0.42 & 0.04 & 0.62 \\
$\operatorname{DVI}_{(950,650)}$ & 0.30 & 0.41 & 0.44 & 0.06 & 0.61 \\
DVI $_{(800,550)}$ & 0.43 & 0.47 & 0.48 & 0.05 & 0.60 \\
$\operatorname{RVI}_{(1100,660)}$ & 0.36 & 0.32 & 0.47 & 0.00 & 0.62 \\
$\operatorname{RVI}_{(950,650)}$ & 0.35 & 0.30 & 0.44 & 0.01 & 0.63 \\
MTVI $_{\text {OSAVI }}$ & 0.40 & 0.51 & 0.43 & 0.04 & 0.54 \\
\hline
\end{tabular}

T=Tillering, $\mathrm{S}=$ Stem elongation, $\mathrm{B}=$ Booting, $\mathrm{H}=$ Heading

Table 3. Coefficient of determination $\left(\mathrm{R}^{2}\right)$ for the relationship between AGB and selected VIs for all three years (2007-2009)

\subsection{Selection of band combinations for the NRI}

Using the method of selecting the best two-band combinations, for estimating rice AGB, new NRIs were established in the domain of 350-1800 nm. Tab. 4 shows the results with the best two-band combination at different growth stages and across all stages. At tillering stage, the AGB is weakly correlated with different band combinations with the highest $\mathrm{R}^{2}$ of 0.34 for $\lambda 1=711 \mathrm{~nm}( \pm 10 \mathrm{~nm})$ and $\lambda 2=799 \mathrm{~nm}( \pm 10 \mathrm{~nm})$. At stem elongation stage, the sensitive bands are mainly located in the SWIR region with three hotspots (Fig. 4), where the best one is at $\lambda 1=1575 \mathrm{~nm}( \pm 10 \mathrm{~nm})$ and $\lambda 2=1678( \pm 10 \mathrm{~nm}) \mathrm{nm}$ with $\mathrm{R}^{2}=0.76$. Another hotspot located close to the water absorption band starting at $1750 \mathrm{~nm}$ may be excluded from the results. Further sensitive bands are centred in the Blue and Red region $\left(R^{2}>0.55\right)$. From this stage to the heading stage, a lower performance of the NRI is observed. At the booting stage, the best band combinations are with $\lambda 1=515 \mathrm{~nm}( \pm 10 \mathrm{~nm})$ in the Green band and $\lambda 2=695( \pm 10 \mathrm{~nm})$ in the Red band. The $\mathrm{R}^{2}$ shows still a good performance $\left(\mathrm{R}^{2}=0.55\right)$. At the last observed stage, heading, the lowest performance of the NRI was observed, but it is obviously better than of the standard VIs. Across all stages, the most promising wavelengths were identified at the Green $(\lambda 1=533) \mathrm{nm}$ and NIR $(\lambda 2=713) \mathrm{nm}$ band with $\mathrm{R}^{2}=0.70$ (Fig. 5, Tab. 4).

\begin{tabular}{llllll}
\hline & \multicolumn{4}{c}{ Stage } \\
& $\mathrm{T}$ & $\mathrm{S}$ & $\mathrm{B}$ & $\mathrm{H}$ & All \\
\hline$\lambda 1$ (in $\mathrm{nm})$ & 711 & 1575 & 515 & 789 & 533 \\
$\lambda 2($ in $\mathrm{nm})$ & 799 & 1678 & 695 & 800 & 713 \\
$\mathrm{R}^{2}$ & 0.34 & 0.76 & 0.55 & 0.27 & 0.70 \\
\hline \multicolumn{2}{l}{$\mathrm{T}=$ Tillering, S=Stem elongation, $\mathrm{B}=$ Booting, $\mathrm{H}=$ Heading }
\end{tabular}

Table 4. Coefficient of determination $\left(\mathrm{R}^{2}\right)$ for the relationship between AGB and NRI for all three years together (2007-2009)

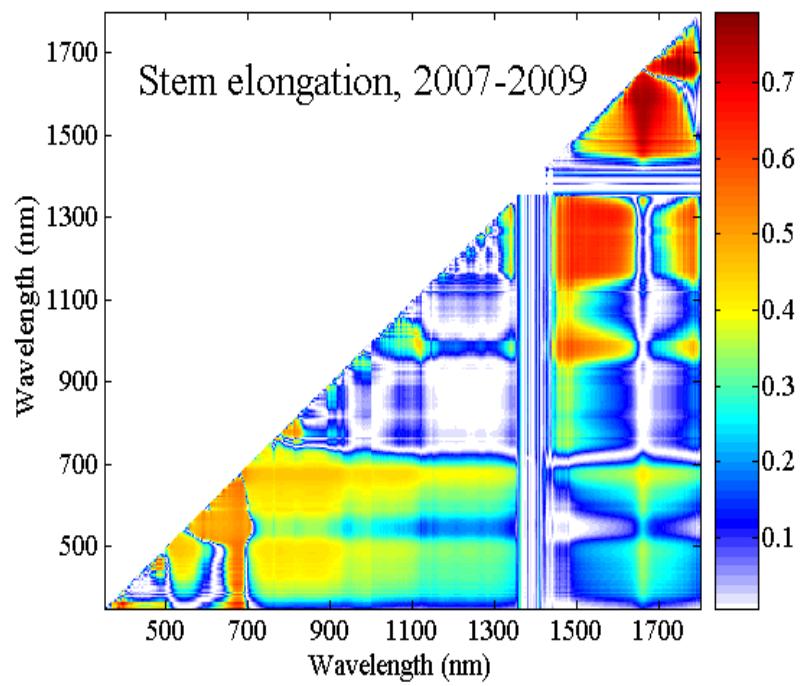

Figure 4. Contour diagram showing the coefficient of determination $\left(\mathrm{R}^{2}\right)$ for the linear relationship between AGB and NRI at stem elongation stage

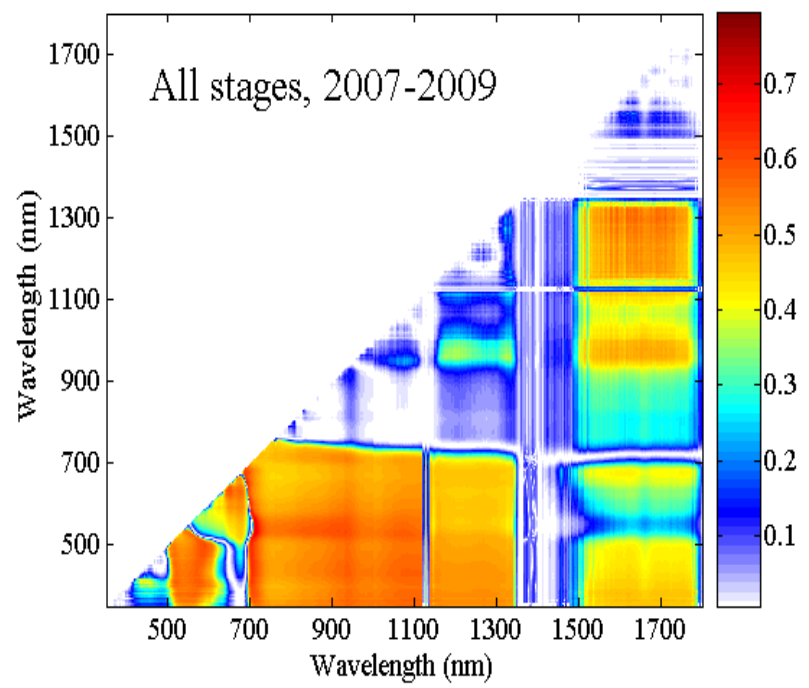

Figure 5. Contour diagram showing the coefficient of determination $\left(\mathrm{R}^{2}\right)$ for the linear relationship between AGB and NRI across all stages

\subsection{Validation of band combinations for the NRI}

When the best two-band combinations for the NRI derived from the experimental field data are applied on the data from farmers' fields, the best combinations are centred in two regions: A small hotspot and the highest $\mathrm{R}^{2}$ value in the Green and NIR region and a broad window in the SWIR region (Fig. 6, Tab. 5). The best performing NRI has the two-band combination with $\lambda 1=554 \mathrm{~nm}( \pm 10 \mathrm{~nm})$ and $\lambda 2=711 \mathrm{~nm}( \pm 10 \mathrm{~nm})$ with a $\mathrm{R}^{2}=0.59$. In the SWIR domain using $\lambda 1$ of $1150-1350 \mathrm{~nm}$ and $\lambda 2$ of $1500-1740 \mathrm{~nm}$, many two-band combinations show high

\begin{tabular}{llll}
\hline Region & $\lambda 1$ (in $\mathrm{nm})$ & $\lambda 2($ in $\mathrm{nm})$ & $\mathrm{R}^{2}$ \\
\hline Green, NIR & 554 & 711 & 0.59 \\
SWIR, SWIR & 1301 & 1701 & 0.58 \\
SWIR, SWIR & 1324 & 1619 & 0.57 \\
\hline
\end{tabular}

Table 5. Best band combinations using farmers' field data across all stages 
$\mathrm{R}^{2}$ values $\left(\mathrm{R}^{2}>0.55\right)$, but are not clearly detectable as a hotspot. Two high performing NRIs are identified, one using $\lambda 1=1301$ and $\lambda 2=1701 \mathrm{~nm}$ with $\mathrm{R}^{2}=0.58$ and another one using $\lambda 1=1324$ and $\lambda 2=1619 \mathrm{~nm}$ with $\mathrm{R}^{2}=0.57$.

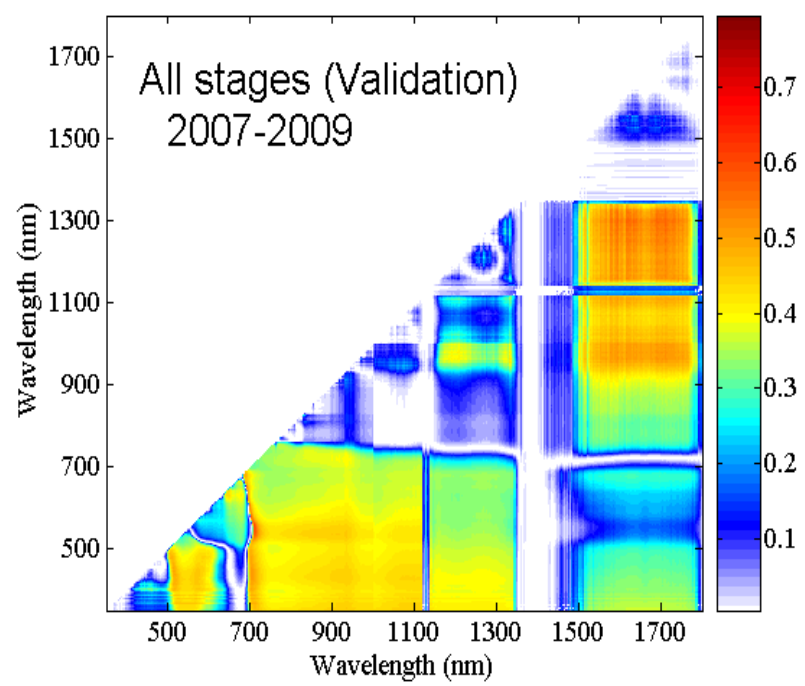

Figure 6. Contour diagram showing the coefficient of determination $\left(\mathrm{R}^{2}\right)$ for the linear relationship between AGB and NRI across all stages applied on farmers' field data

\section{DISCUSSION}

Many studies revealed that various VIs, especially standard VIs such as NDVI or RVI, tend to asymptotically saturate in response to high AGB or LAI (Thenkabail et al., 2000; Chen et al. 2009). The best two-band combination was applied in this study to overcome this saturation. The results show a better performance of the NRI than of the selected standard VIs at the growth stages stem elongation, booting and heading, but a similar result for NRI $\left(\mathrm{R}^{2}=0.70\right)$ and NDVI $\left(\mathrm{R}^{2}=0.68\right)$ across all stages (Tab. 3 and Tab. 4). In the early stage tillering, the NRI cannot exceed the standard VIs to estimate AGB. The validation of the NRI $(554,711)$ using farmers' field data shows a lower performance $\left(R^{2}=0.59\right)$. However, this NRI has very similar bands as the NDVI $(565,708)$ proposed by Hansen \& Schoerring (2003). Across all stages, the NRI is the best estimator for paddy rice AGB.

The sensitive bands in this study are similar to optimal wavelengths $(554,675,723,1633 \mathrm{~nm})$ for paddy rice LAI estimation which were reported by Wang et al. (2008). Two of these wavelengths (675 and $723 \mathrm{~nm}$ ) can be defined as red-edge bands. Herrmann et al. (2011) showed that red-edge bands are important for LAI assessment as well as that the REIP is not saturated. LAI and AGB are strongly correlated, especially in the early growth season, as long the head and grain of the plant are not developed. For this reason, VIs developed for LAI estimation such as TVI, can be used to estimate AGB.

In agreement with the previous study by Shibayama \& Munakata (1989) for rice AGB estimation, the performance of the NRI is similar, but using different bands for NRI, DVI or RVI compared to this study $(480,560,660,840,1100 \mathrm{~nm})$. It seems that the sensitive bands are shifted depending on the cultivar of one crop. This is also reported in many studies (e.g. Nguyen et al., 2006; Gnyp et al., 2009). Koppe et al. (2010) also used one band in the SWIR $(1225 \mathrm{~nm})$ and one in NIR
$(874 \mathrm{~nm})$ for AGB estimation of winter wheat and reached a high performance of the NRI. Also for grassland AGB estimation, the best two-band combinations were identified mostly in the SWIR (1084, 1172, 1205, 1326, $1715 \mathrm{~nm})$ by Psomas et al., 2011.

However, there are still many questions to be answered before this approach can be applied in agricultural practice. One of them is, why the SWIR bands centred at $1575 \mathrm{~nm}$ and $1678 \mathrm{~nm}$ show such a good performance for estimating AGB at the stem elongation stage, although one of the bands is located near to the water absorption band? This band may produce wrong reflectance values using the spectroradiometer under solar light conditions. On the other hand there is a lot of water in the field and the canopy cover is not very dense at tillering and stem elongation stages. At these stages, the water reflectance could account for a proportion of the reflectance. At later stages, the AGB production is much higher and the canopy cover much more dense so that the effect can be excluded. Besides, the SWIR domain is related to plant water content (Hunt, 1991). Shibayama \& Munakata (1989) reported the potential of two SWIR bands $(1200 \mathrm{~nm}$ and $1650 \mathrm{~nm})$ for plant status analyses. They compared the reflectance of a rice canopy and a paddy field without water and showed that the SWIR domain in rice is influenced by plant water content or by soil sediment.

In summary, the results of this study highlight the challenge of hyperspectral analysis of rice biomass. Additional two-band combination analysis of the best DVI and RVI would be of high value to compare these methods and to detect the best method for rice AGB estimations or other agronomic parameters at different stages or across all stages for this study area. Due to the promising MLR analyses by Yang et al. (2004), and PLS analysis by Nguyen et al. (2006) for estimating paddy rice AGB or LAI at different phenological stages, these methods will be applied on the presented data set.

\section{CONCLUSION}

The study evaluated eight selected standard VIs AGB and all possible two-band combinations for the NRI in the wavelength domain of 350-1800 $\mathrm{nm}$ for estimating paddy rice at different growth stages and across all stages, using hyperspectral data of three years. The results indicate varied sensitive wavelengths for different stages, using Green, Red and NIR bands for tillering, booting and heading stages, and Green, NIR and SWIR bands for stem elongation stage. Across all stages and all years, the NRI is the best performing VI compared to the selected standard VIs, except for the tillering stage. Moreover, measurements of paddy rice in a laboratory are needed, especially in the SWIR domain around the water absorption band to investigate the sensitive bands located closely to that region.

\section{REFERENCES}

Buschmann, C., Nagel, E. 1993. In vivo spectroscopy and internal optics of leaves as basis of remote sensing of vegetation. INT J REMOTE SENS, 14 (4), pp. 711-722.

Chen, J., Gu, S., Shen, M., Tang, Y., Matsushita, B., 2009. Estimating aboveground biomass of grassland having a high canopy cover: an exploratory analysis of in situ hyperspectral data. INT J REMOTE SENS, 30 (24), pp. 6497-6517. 
Gnyp, M. L., Li, F., Miao, X., Koppe, W., Jia, L., Chen, X., Zhang, F., Bareth, G., 2009. Hyperspectral data analysis of $\mathrm{N}$ fertilization effects on winter wheat using spectrometer in North China Plain. IEEE Proc. 1st Workshop on Hyperspectral Image and Signal Processing: Evaluation in Remote Sensing, 26-28 August 2009, Grenoble, France, pp. 255-258.

Haboudane, D., Miller, J. R., Pattey, E., Zarco-Tejada, P. J., Strachan, I. B. 2004. Hyperspectral vegetation indices and novel algorithms for predicting green LAI of crop canopy: Modeling and validation in the context of precision agriculture. REMOTE SENS ENVIR, 90 (3), pp. 337-352.

Hansen, P. M., Schjoerring, J. K., 2003. Reflectance measurement of canopy biomass and nitrogen status in wheat crops using normalized difference vegetation indices and partial least squares regression. REMOTE SENS ENVIR, 86 (4), pp. 542-553.

Herrmann, I., Pimstein, A., Karnieli, A., Cohen, Y., Alchanatis, V., Bonfil, D. J., 2011. LAI assessment of wheat and potato crops by VEN $\mu \mathrm{S}$ and Sentimel-2 bands. REMOTE SENS ENVIR, 115 (8), pp. 2141-2151.

Hunt, E. R., 1991. Airborne remote sensing of canopy water thickness scaled from leaf spectrometer data. INT J REMOTE SENS, 12 (3), pp. 643-649.

Koppe, W., Li, F., Gnyp, M. L., Miao, Y., Jia, L., Chen, X., Zhang, F., Bareth, G., 2010. Evaluating multispectral and hyperspectral satellite remote sensing data for estimating winter wheat growth parameters at regional scale in North China Plain. PFG, 3, pp. 167-178.

Laudien, R., Burky, K., Doluschitz, R., Bareth, G., 2006. Establishment of a Web-based spectral database for the analysis of hyperspectral data from Rhizoctonia solani-inoculated sugarbeets. ZUCKERINDUSTRIE, 131(3), pp. 164-170.

Lenz-Wiedemann, V. I. S., Klar, C. W., Schneider, K., 2010. Development and test of a crop growth model for application within a Global Change decision support system. ECOL MODEL, 221(2), pp. 314-329.

Li, F., Miao, Y., Hennig, S. D., Gnyp, M. L., Chen, X., Jia, L., Bareth, G., 2010. Evaluating hyperspectral vegetation indices for estimating nitrogen concentration of winter wheat at different growth stages. PREC AGRIC, 11 (4), pp. 335-357.

Milton, E. J., Schaepman, M. E., Anderson, K., Kneubühler, M., Fox, N., 2009. Progress in field spectroscopy. REMOTE SENS ENVIR, 113, pp. S92-S109.

Nguyen, H. T., Kim, J. H., Nguyen, A. T., Shin, J. S., 2006. Using canopy reflectance and partial least squares regression to calculate within-field statistical variation in crop growth and nitrogen status of rice. PREC AGRIC, 7 (4), pp. 249-264.

Osborne, S. L., Schepers, J. S., Francis, D. D., Schlemmer, M. R., 2002. Use of spectral radiance to estimate in-season biomass and grain yield in nitrogen and- water-stressed corn. CROP SCI, 42, pp. 165-171.

Psomas, A., Kneubühler, M., Huber, S., Itten, K., Zimmermann, N. E., 2011. Hyperspectral remote sensing for estimating aboveground biomass and for exploring species richness patterns of grassland habitats. INT J REMOTE SENS, 32 (24), pp. 9007-9031.

Rondeaux, G., Steven, M., Baret, F., 1996. Optimization of soil-adjusted vegetation indices. REMOTE SENS ENVIR, 55 (2), pp. 95-107.

Serrano, L., Filella, I., Penuelas, J., 2000. Remote sensing of biomass and yield of winter wheat under different nitrogen supplies. CROP SCI, 40 (3), pp. 723-731.

Shibayama, M., Munakata, K., 1986. A spectroradiometer for field use III: A comparision of some vegetation indices for predicting luxuriant paddy rice biomass. JPN J CROP SCI, 55 (1), pp. 47-52.

Shibayama, M., Munakata, K., 1989. Seasonal visible, nearinfrared and mid-infrared spectra of rice canopies in relation to LAI and above-ground dry phytomass. REMOTE SENS ENVIR, 27 (2), pp. 119-127.

Song, S., Gong, W., Zhu, B., Huang, X., 2011. Wavelength selection and spectral discrimination for paddy rice with laboratory measurements of hyperspectral leaf reflectance. INT SOC PHOTOGRAMME, 66 (5), pp. 672-682.

Stroppiana, D., Boschetti, M., Brivio, P. A., Bocchi, S., 2009. Plant nitrogen concentration in paddy rice from canopy hyperspectral radiometry. FIELD CROP RES, 111 (1-2), pp. 119-129.

Thenkabail, P. S., Smith, R. B., Pauw, E. D., 2000. Hyperspectral vegetation indices and their relationship with agricultural crop characteristics. REMOTE SENS ENVIR, 71 (2), pp. 152-182.

Tian, Y. C., Yao, X., Yang, J., Cao, W. X., Hannaway, D. B., Zhu, Y., 2011. Assessing newly developed and published vegetation indices for estimating rice leaf nitrogen concentration with ground- and space-based hyperspectral reflectance. FIELD CROP RES, 120 (2), pp. 299-310.

Todd, S.W., Hopper, R. M., Milchunas, D. G., 1998. Biomass estimation on grazed and ungrazed ranglands using spectral indices. INT J REMOTE SENS, 19 (3), pp. 427-428.

Wang, F., Huang, J., Zhou, Q., Wang, X., 2008. Optimal waveband identification for estimating of leaf area index of paddy rice. J ZHEJIANG UNIV-SC B, 9 (12), pp. 953- 963.

Yang, C., Chen, R., 2004. Modeling rice growth with hyperspectral reflectance data. CROP SCI, 44 (4), pp. 12831290.

Zhu, Y., Yao, X., Tian, Y., Liu, X., Cao, W., 2008. Analysis of common canopy vegetation indices for indicating leaf nitrogen accumulation wheat and rice. INT J APPL EARTH OBS, 10 (1), pp. 1-10.

\section{ACKNOWLEDGEMENTS}

This research was financially supported by the International Bureau of the German Federal Ministry of Education and Research (BMBF, Project number CHN 08/051), Natural Science Foundation of China (31071859), and Chinese Universities Scientific Fund (2012QJ162). 